\title{
Impactos do Protocolo de Cartagena sobre o Comércio de Commodities Agrícolas
}

\author{
Izaías de Carvalho Borges ${ }^{1}$, José Maria F.J. da Silveira², José Eustáquio Vieira Filho ${ }^{3}$ e Andrea M. Pereira ${ }^{3}$
}

O Protocolo de Cartagena sobre Biossegurança é um acordo ambiental que agrega 132 países. O Protocolo tem impactos sobre o comércio de commodities agrícolas, porque estabelece regras para o transporte entre fronteiras de organismos vivos modificados (OVMs). O Artigo 18.2(a) do Protocolo refere-se às formas de identificação dos OVMs nos carregamentos de commodities agrícolas. O fato de que os principais países exportadores de grãos também sejam produtores de cultivares geneticamente modificados torna relevante a discussão sobre os possíveis impactos derivados do processo de implementação e a avaliação dos distintos impactos que possam ocorrer segundo a posição ocupada pelos países no mercado internacional (exportadores / importadores). O artigo também trata dos custos envolvidos com a adaptação interna dos países, que são em grande parte determinados pela infra-estrutura de armazenamento e transporte. Estes custos poderão variar de acordo com os tipos de regras estabelecidas pelo Protocolo.

\section{Impact of the Cartagena Protocol on the Trade of Agricultural Commodities}

The Cartagena Protocol on Biosafety is an environmental agreement signed by 132 countries as parties. Important topics will lead to the Protocol's implementation. One of the main issues of the negotiations was the debate on how to apply Article 18.2(a), which will require identification of the living modified organisms (LMOs) subject to international transboundary movements. Considering that grain exporters like Brazil cultivate LMOs, it is extremely important to discuss possible impacts of the Protocol's implementation and the different economic impacts according to the country's position in the international market (net exporter, importer). The article also raises some aspects, such as costs involved with internal changes in logistics and infrastructure of every country that will be needed in order to comply with the identification requirements of the Protocol.

Key words: agriculture biotechnology, biosafety, impacts on trade

\footnotetext{
${ }^{1}$ CEA/PUCCAMP e Núcleo de Economia Agrícola e Ambiental - NEA/ Instituto de Economia - IE (UNICAMP)

${ }^{2}$ Núcleo de Economia Agrícola e Ambiental - NEA/ Instituto de Economia - IE (UNICAMP) e GEOPI/IG/UNICAMP

${ }^{3}$ Núcleo de Economia Agrícola e Ambiental - NEA/ Instituto de Economia - IE (UNICAMP)
} 


\section{Introdução}

Em março de 2006, na cidade de Curitiba (Paraná, Brasil), foi realizada a terceira reunião das partes $^{5}$ do Protocolo de Cartagena sobre Biossegurança. A relevância desta reunião e das que se seguirão nos próximos anos está no fato de que as suas determinações poderão afetar o comércio mundial de commodities agrícolas.

O Protocolo de Cartagena sobre Biossegurança tem por objetivo a proteção da diversidade biológica frente aos avanços da biotecnologia moderna. A reunião realizada em Curitiba buscou chegar a um acordo sobre um tema controverso: o estabelecimento de regras de segurança para o transporte entre fronteiras de organismos vivos modificados. Com a importância crescente das variedades geneticamente modificadas na produção das principais commodities agrícolas, a implementação do Protocolo poderá causar impactos significativos no comércio internacional.

O Protocolo prevê em seu artigo $1^{\circ}$ que, para atingir seus objetivos, deve ser considerado o "princípio da precaução", também presente na Declaração do Rio, de 1992. Este princípio enfatiza que a falta de certeza científica não deve servir de motivação para que medidas de precaução deixem de ser adotadas. Criou-se, então, uma base de conflito entre a visão estritamente ambientalista do problema de biossegurança e aquela fundamentada nos ganhos de produtividade resultantes da adoção de inovações tecnológicas.

Tal diferença de visões gerou ambigüidades (concebida como elemento de incerteza, segundo Hall \& Martin, 2003) e aumentou a importância das reuniões do Protocolo de Cartagena (PCB), uma vez que posicionou em lados opostos países exportadores de Organismos Vivos Modificados (OVMs) - principalmente grãos - e países importadores. Em posição intermediária, estão os países simultaneamente biodiversos e exportadores, como o Brasil, que com isto tornaram-se ícones desta ambigüidade. A expectativa - um tanto heróica - de que o problema possa ser resolvido durante as sucessivas Meetings of the Parties, MOP - está baseada na suspeita de que o lado "ambientalista" tenha privilégios, uma vez que o PCB surgiu no escopo da proteção ambiental.

O presente trabalho tem como objetivo mostrar que a forma de regulamentar a questão, envolvendo apenas o artigo 18 2.a do Protocolo de Cartagena, pode implicar em expressivas mudanças no panorama do comércio de alguns produtos agrícolas e que, portanto, as decisões tomadas pela futura MOP, que devem finalmente regulamentar o artigo, precisam levar em conta os aspectos econômicos envolvidos.

O trabalho está centrado na cultura da soja, por sua importância e pela difusão de cultivares GM tolerantes a herbicidas em várias regiões produtoras do Brasil. Apresenta também distintas avaliações de impactos nos principais países exportadores. Estas avaliações, no entanto, não têm a preocupação de integrá-los por meio de uma análise que avalie sua repercussão em nível internacional, uma vez que para isto será necessário um estudo pormenorizado.

Na seção 2, efetua-se uma breve apresentação do Protocolo de Cartagena, descrevendo seus objetivos, a fase atual da sua implementação e de que forma ele poderá afetar o comércio. Na seção 3, apresenta-se um resumo da evolução recente da biotecnologia agrícola e sua importância para a discussão do processo de implementação das regras do PCB. Na seção 4, são fornecidas as bases econômicas do conflito que permeia a discussão e o processo de regulamentação do PCB. Na seção 5, apresenta-se o resultado de estudos empíricos sobre o tema, adotando três pontos de referência: a natureza das exigências regulatórias, o impacto no comércio internacional de grãos e a adaptação interna dos países ao PCB. E finalmente na seção 6, reúnese as conclusões do trabalho.

\section{O Protocolo de Cartagena sobre Biossegurança}

O Protocolo de Cartagena sobre Biossegurança (PCB) é um acordo ambiental que teve origem na Convenção sobre Diversidade Biológica

\footnotetext{
${ }^{5}$ São considerados partes todos os países que ou ratificaram, ou consentiram e/ou assinaram o Protocolo.
} 
(CDB), estabelecida pela Conferência sobre Meio Ambiente e Desenvolvimento das Nações Unidas em 1992. A criação de um acordo ambiental com o objetivo de regulamentar a utilização de OVMs estava prevista no Artigo 19.3 da CDB, no qual foi estabelecido que:

"As partes devem examinar a necessidade e as modalidades de um protocolo que estabeleça procedimentos adequados, inclusive e em especial, a concordância prévia, fundamentada no que diz respeito à transferência, manipulação e utilização seguras de todo organismo vivo modificado pela biotecnologia, que possa ter efeito negativo para a conservação e utilização sustentável da diversidade biológica”.

Este acordo previsto na CDB foi estabelecido em 2000, com a aprovação do Protocolo de Cartagena sobre Biossegurança que passou a vigorar em setembro de 2003. No Brasil, o Protocolo foi aprovado pelo Congresso Nacional no mesmo ano.

O Protocolo é uma das ferramentas para a implementação da CDB e é o primeiro acordo internacional com o objetivo de estabelecer regras para a transferência, manejo e o uso de OVMs.

O objetivo geral do PCB é "contribuir para assegurar um nível adequado de proteção no campo da transferência, da manipulação e do uso seguro dos organismos vivos modificados, resultantes da biotecnologia moderna, que possam causar efeitos adversos na conservação e no uso sustentável da diversidade biológica, levando em conta os riscos para a saúde humana e enfocando, especificamente, os movimentos transfronteiriços" (CTNBio, 2006) ${ }^{6}$. Em termos específicos, os objetivos do Protocolo são:

- a criação, na internet, de uma "Central de Informações sobre Biossegurança (Biosafety ClearingHouse), para que os países possam trocar informações referentes às autorizações de cultivo e de importação de organismos vivos modificados (OVMs), destinados à alimentação humana, animal e ao processamento e também referentes às legislações de cada País parte sobre biossegurança.

- a criação de um mecanismo de Acordo Prévio Informado (Advance Informed Agreement - AIA), para que os países importadores possam decidir quanto à importação de um OVM que será introduzido no meio ambiente, como: sementes para plantio, animais para comercialização ou microrganismos para biorremediação.

- a conscientização do público para uma maior participação nos processos referentes à segurança do transporte e do manuseio dos OVMs em relação à conservação e ao uso sustentável da biodiversidade.

- o desenvolvimento de recursos humanos e de capacidade institucional em biossegurança da biotecnologia moderna nos países signatários do Protocolo, principalmente nos países em desenvolvimento.

Até 2006, foram realizadas três reuniões das Partes, denominadas Meeting of the Parties, $\mathrm{MOP}^{7}$. Nestas reuniões, os procedimentos que orientam a implantação de seus artigos são aprovados, consensualmente, pelos países signatários. A primeira Conferência das Partes do Protocolo (COP/MOP1) foi realizada em Kuala Lumpur (Malásia), em fevereiro de 2004. A COP/MOP1 contou com a participação de representantes de 160 países e o foco das discussões foi o conjunto de aspectos operacionais e institucionais referentes à implantação do Protocolo. A segunda reunião do Protocolo (COP/MOP2) ocorreu em maio/junho de 2005, em Montreal (Canadá). Com a participação de mais de 100 países, os principais temas da reunião foram: “O detalhamento das informações referentes à identificação dos carregamentos de OVMs, destinados à alimentação humana, animal e ao processamento (Artigo 18, parágrafo 2 [a]); a avaliação da possibilidade de criação de um regime de responsabilidade e compensação (Artigo 27); a implantação do Biosafety Clearing-House, previsto no

\footnotetext{
${ }^{6}$ A principal polêmica envolvendo cargas de grãos está relacionada ao movimento, transporte, embalagem e identificação, para usar o jargão do PCB. Ver CIB (2006).

7 As "MOP" ocorrem conjuntamente com a Conference of the Parties - COP.
} 
Artigo 20; e Artigo 22 - Criação de Capacidade (física e humana) necessária à consecução dos objetivos do Protocolo" (CIB, 2006).

A terceira e a mais importante reunião das Partes ocorreu em março de 2006, em Curitiba (Brasil). O foco das discussões da COP-MOP/3 foi a identificação das cargas, destinadas a exportação, contendo OVMs. No texto original do Protocolo, foi usada a expressão "pode conter" para a identificação de cargas contendo OVMs. Porém, grande parte dos países importadores de commodities agrícolas defenderam que a identificação fosse feita com o termo "contém OVMs". Entretanto, para os países exportadores, a escolha da forma de identificar é fundamental porque ela poderá acarretar custos extras. O uso do termo "contém OVMs", como querem os países importadores, implicaria numa identificação muito detalhada e exigiria a realização de testes sofisticados, aumentando, substancialmente, os custos para os países exportadores.

Antes de iniciar a MOP3, o Brasil aliava-se apenas à Nova Zelândia na defesa da expressão "pode conter". Com a proximidade da reunião, países da América Central, liderados pelo México e alguns pequenos produtores de soja, como o Paraguai, mudaram sua posição por constatar que, dependendo da forma de regulação, a expressão "contém" poderia inviabilizar a participação no comércio internacional. Como será visto adiante, tal expectativa coincide com os resultados de trabalhos realizados pelo International Policy Council - que apontaram a probabilidade de custos elevados e impactos significativos, devidos à implementação da expressão "contém em diferentes países, inclusive países não-Parte”.

Vale lembrar que, apesar da sistemática das reuniões resultar na análise de cada artigo, reconhecese a articulação entre a questão relativa à “identificação de cargas", presente no artigo 18.2[a], e aquelas relativas à imputação de responsabilidade e compensação do artigo 27 . Um sistema de imputação de responsabilidade e compensação deveria ser apoiado na aplicação de métodos de segregação e rastreabilidade capazes de indicar a origem de um problema, caso ele tivesse se originado na agricultura e não em erros de manuseio no país de destino. Portanto, a escolha de um sistema de responsabilização objetiva ou "por culpa" condicionaria a decisão sobre o manuseio, transporte, embalagem e identificação de $\mathrm{OVMs}^{8}$. Todavia, esta discussão ficou para a próxima MOP, programada para 2008, uma vez que as partes reconheceram a falta de conhecimento necessário para tratar do problema na reunião de Curitiba.

\section{Um Panorama da Evolução Recente da Biotecnologia Agrícola}

Os cultivos GM começaram a ser produzidos em grande escala, a partir de 1996, nos Estados Unidos. Desde então, a taxa de difusão de cultivos GM, neste e em outros países, tem sido elevada em comparação com outras tecnologias agrícolas. Estima-se que a área mundial de cultivos GM aumentou de 2,8 milhões de hectares em 1996, para 90 milhões de hectares em 2005 (JAMES, 2006). A elevada taxa de difusão dos cultivos GM relacionase às seguintes vantagens propiciadas pelo uso dos cultivares transgênicos: a) redução do custo de produção, estimado na faixa de 5 a $10 \%$ em vários estudos de avaliação (SILVEIRA, BORGES \& BUAINAIN, 2005); b) redução na aplicação de pesticidas e inseticidas, principalmente no caso de cultivares resistentes a insetos; c) melhor planejamento das atividades agrícolas, com aperfeiçoamento da articulação entre o controle de ervas daninhas, pragas e as práticas de cultivo mínimo.

Até o momento, a difusão dos cultivos GM

\footnotetext{
${ }^{8}$ Em nosso ponto de vista, a escolha de um sistema de responsabilização objetiva constituiria uma moratória à pesquisa em biotecnologia. Ambientalistas radicais, antitransgênicos, defendem a adoção deste sistema, ao contrário do ponto de vista dos pesquisadores e das empresas de biotecnologia e sementes. Por exemplo, aquele que recebesse uma carga de OVMs para processamento e dirigisse ilegalmente um lote para o cultivo em seu país, no sistema "por culpa” seria o responsável por algum tipo de perda de biodiversidade que porventura viesse a ocorrer. Porém, o sistema de "responsabilidade objetiva" atribuiria ao centro de pesquisa criador do transgene o ônus do possível acidente, independentemente do erro ter sido cometido longe dali, por outro participante da cadeia produtiva. Ver Amâncio, apud CIB (2006).
} 
concentrou-se em "produtos de plataforma", ou seja, grupos de commodities com um grande volume de comércio mundial. Segundo James (2006), os 90 milhões de hectares produzidos com cultivos GM estão divididos entre quatro grupos de commodities: soja, milho, algodão e canola. Dos quatro produtos, a soja e o milho ocupam $84 \%$ da área mundial cultivada com variedades GM. Portanto, o uso de organismos geneticamente modificados na agricultura está concentrado na produção de poucos tipos de grãos, sendo que os quatro principais cultivos de grãos - arroz, milho, soja e trigo - ocupam cerca de $50 \%$ de toda terra arável do mundo (FAOSTAT, 2006).

De imediato, o PCB afetaria, com maior intensidade, os mercados de soja e milho, produtos com grande participação na produção agrícola mundial. A produção mundial de soja aumentou de 31 milhões de toneladas em 1965, para 209,5 milhões de toneladas em 2005. Apesar do crescimento constante no período, após 1975, a taxa de crescimento da produção foi decrescente até 1995 , voltando a subir na década de 1995 a 2005, período em que a soja GM começou a ser adotada pelos principais produtores mundiais. De 1995 a 2005, a produção mundial de soja cresceu $65 \%$. No caso do milho, também houve um grande aumento da produção entre 1965 e 2005. Dentre o grupo de cereais, o milho foi o que apresentou a maior taxa de crescimento neste período, aumentando a sua participação na produção mundial de cereais de 22\% em 1965, para 32\% em 2005 (FAOSTAT, 2006).

Este expressivo crescimento da produção de grãos e de cereais nos últimos 40 anos é explicado pelo aumento da demanda por alimentos, que por sua vez é justificado pelo crescimento populacional e pelo desenvolvimento econômico. No caso específico da soja e do milho, o crescimento da produção está relacionado com o aumento da demanda por carne, uma vez que grande parte da produção destes dois produtos é utilizada para a alimentação animal. No caso do milho, por exemplo, cerca de $70 \%$ da produção global é direcionada para consumo animal. Os ganhos tecnológicos - de pequena monta, por unidade de produto,multiplicados por um elevado coeficiente de adoção dos cultivares transgênicos em cultivos de grande importância para o comércio internacional, do ponto de vista econômico, garantem a relevância da inovação tecnológica. Ao mesmo tempo, por seu alcance especial, vêm motivando a oposição de grupos ambientalistas, de defesa de consumidores, e alguns representantes de organizações relacionadas à saúde pública.

Em 2005, de acordo com os dados apresentados na Tabela 1, os cultivos GM eram adotados nos principais países exportadores de commodities agrícolas. Os cinco maiores produtores de cultivos GM no mundo - Estados Unidos, Argentina, Brasil, Canadá e China -, juntamente com a União Européia, são os principais atores do comércio agrícola mundial.

Tabela 1. Países produtores de cultivos geneticamente modificados em 2005

\begin{tabular}{|c|c|c|c|}
\hline Posição & País & Área & Lavouras GM \\
\hline 1 & EUA & 49,80 & $\begin{array}{l}\text { Soja, milho, algodão, } \\
\text { canola, abóbora, }\end{array}$ \\
\hline 2 & Argentina & 17,10 & Soja, milho, algodão \\
\hline 3 & Brasil & 9,40 & Soja \\
\hline 4 & Canadá & 5,80 & Canola, milho, algodão \\
\hline 5 & China & 3,30 & Algodão \\
\hline 6 & Paraguai & 1,80 & Soja \\
\hline 7 & Índia & 1,30 & Algodão \\
\hline 8 & África do Sul & 0,50 & Milho, soja, algodão \\
\hline 9 & Uruguai & 0,30 & Soja, milho \\
\hline 10 & Austrália & 0,30 & Algodão \\
\hline 11 & México & 0,10 & Algodão, soja \\
\hline 12 & Romênia & 0,10 & Soja \\
\hline 13 & Filipinas & 0,10 & Milho \\
\hline 14 & Espanha & 0,10 & Milho \\
\hline 15 & Colômbia & $<0,1$ & Algodão \\
\hline 16 & Irã & $<0,1$ & Arroz \\
\hline 17 & Honduras & $<0,1$ & Milho \\
\hline 18 & Portugal & $<0,1$ & Milho \\
\hline 19 & Alemanha & $<0,1$ & Milho \\
\hline 20 & França & $<0,1$ & Milho \\
\hline 21 & $\begin{array}{l}\text { República } \\
\text { Tcheca }\end{array}$ & $<0,1$ & Milho \\
\hline
\end{tabular}

Fonte: James, 2006.

Um mapeamento da situação da pesquisa com biotecnologia agrícola, elaborado por Runge \& Ryan (2004), mostra que a transgenia poderá ser utilizada em outros segmentos além da produção de grãos. 
Como mostra o Quadro 1, as pesquisas e os experimentos com transgenia estão se difundindo por um conjunto muito amplo de cultivos e de países. Em 2004, as pesquisas com transgenia estavam presentes em 57 grupos de cultivos, incluindo grãos, frutas, legumes e hortaliças. Dentre eles, estão cultivos de grande representatividade no mercado mundial de commodities agrícolas, tais como: café, arroz, trigo, cana-de-açúcar e laranja.

Quadro 1. Cultivos Geneticamente Modificados produzidos comercialmente e em fase de pesquisas

\begin{tabular}{|c|c|c|c|}
\hline & Produtos & Atributos & $\begin{array}{c}\text { No } \\
\text { de Países }\end{array}$ \\
\hline $\begin{array}{c}\text { Cultivos GM } \\
\text { produzidos } \\
\text { atualmente }\end{array}$ & $\begin{array}{c}\text { Algodão, Canola, } \\
\text { Milho e Soja }\end{array}$ & $\begin{array}{c}\text { Tolerância a herbicidas e } \\
\text { Resistência a insetos }\end{array}$ & 21 \\
\hline $\begin{array}{c}\text { Cultivos em fase } \\
\text { de pesquisas de } \\
\text { laboratório e de } \\
\text { campo }\end{array}$ & $\begin{array}{c}\text { algodão, café, feijão, arroz, milho, } \\
\text { strigo, tabaco, cenoura, tomate, } \\
\text { batata, palmito, coco, cana-de- } \\
\text { açúcar, laranja, mamão, melão, } \\
\text { banana, maçã, manga. }\end{array}$ & $\begin{array}{c}\text { Atributos Agronômicos: } \\
\text { resistência a insetos, a vírus } \\
\text { e fungos; tolerância a seca e } \\
\text { tolerância a herbicidas } \\
\text { Atributos Especiais: } \\
\text { modificações nas características } \\
\text { nutricionais (maior quantidade } \\
\text { de vitaminas, por exemplo }\end{array}$ & 60 \\
\hline
\end{tabular}

Fonte: James, 2006; Runge \& Ryan, 2004.

Espera-se, portanto, que a evolução da biotecnologia agrícola tenha como conseqüência a maior difusão de cultivares transgênicos em volume, área de alcance e número de eventos distintos contidos em grãos comercializados ${ }^{9}$. Em uma situação em que reduzidos cultivos com poucos eventos transgênicos, a regulamentação do Protocolo é marcada pela incerteza e pelo uso exacerbado do "princípio da precaução", no que tange à definição de regras para identificação dos OVMs destinados à exportação. Cria-se com isto uma situação de conflito, cujas bases são apresentadas a seguir.

\section{As bases econômicas do conflito em torno da implementação do PCB}

O conflito em torno das duas expressões "pode conter" e "contém", cujos significados foram explicitados na seção 2, é balizado pelos seguintes pontos:

a) os carregamentos de grãos, usados para alimentação humana, animal e para processamento, são embarcados a granel, manejados em lotes de grande volume, tanto nas operações de armazenagem, quanto de transporte;

b) a presença acidental ou tecnicamente inevitável de OVMs irá ocorrer nas movimentações de commodities internas e transfronteiriças, originadas dos países produtores de cultivares geneticamente modificados. Regiões com maior "mescla" de cultivos transgênicos e não-transgênicos apresentam maiores dificuldades para cumprir exigências do PCB;

c) o custo para identificação de lotes varia de

\footnotetext{
${ }^{9}$ Um evento corresponde à inserção de um gene para determinado atributo em um cultivar. Um cultivar pode ter mais de um evento, o que já acontece com variedades transgênicas de milho, soja e algodão. Como será tratado adiante, quanto maior o número de eventos em um mesmo lote, mais custosas serão as aplicações de testes para a quantificação necessária para identificar cargas destinadas à exportação.

${ }^{10} \mathrm{O}$ nível de 1,0\% para "presença adventícia" significa que, após a aplicação de testes, um lote com mais de 1 grão em 100 passaria a ser considerado "lote transgênico". Pelos objetivos do PCB, isto significa comunicar que o lote é transgênico. Pela lei de rotulagem, caso o produto fosse consumido diretamente (como se fosse amendoim torrado), a embalagem, de acordo como os padrões da EU, deveria acusar a condição do produto de "elaborado com soja geneticamente modificada". Confundir identificação de OVMs com rotulagem foi um equívoco alimentado por alguns militantes ambientalistas e grupos antitransgênicos, durante a MOP3. Todavia, há grande diferença entre um produto que ainda será processado e outro que será consumido como alimento.

${ }^{11} \mathrm{O}$ que significa considerar cultivares que sejam distintos em função de incorporarem um ou mais transgenes e não cultivares diferentes com o mesmo gene modificado.
} 
acordo com o grau de exigência definido pelos reguladores: níveis de tolerância mais altos para definição de um lote como transgênico implicam em menos cuidados no processo de transporte e armazenamento do que níveis mais baixos, ou seja, mais exigentes; ${ }^{10}$

d) o quanto maior o número de cultivares transgênicos ${ }^{11}$ de uma mesma cultura, maiores os custos de aplicação de testes e maiores os cuidados e exigências para evitar a presença adventícia, se o sistema de informação adotado pelo PCB exigir uma documentação detalhada, baseada em testes e, indo mais longe, certificados de origem de cada cultivar.

Os pontos apresentados anteriormente delineiam dois parâmetros básicos para o processo de regulação e para a mensuração de impactos econômicos: a) o nível de tolerância para a presença acidental de eventos não-aprovados, e/ou eventos em testes finais de campo e/ou eventos aprovados no país exportador, mas não no país de destino; b) o grau de exigência do processo de identificação das cargas transgênicas para exportação, se qualitativo ou quantitativo, baseado apenas em testes ou demandando a implantação de sistemas de PI.

Adicione-se às dificuldades acima o fato de que muitos países importadores têm tolerância zero

Quadro 2. Resumo dos Métodos de Análise de OVMs para eventos não-aprovados, implicando em um custo elevado de identificação de cargas. Para alguns países, entre eles o Brasil, em que "sementes piratas" ainda são utilizadas por agricultores, tal comportamento pode resultar na necessidade de implantação de sistemas - soft ou hard - de rastreamento e de segregação ${ }^{12}$.

O Quadro 2 apresenta um resumo dos tipos de métodos ou testes utilizados para a identificação de OVMs. Estes métodos são divididos em dois grupos: os métodos baseados na análise de DNA e os métodos baseados na análise / identificação de proteínas. Os métodos baseados na análise de DNA, além de mais caros, são mais demorados, não podem ser realizados no campo e exigem maior infra-estrutura de instalação e de operação dos equipamentos e de conservação dos reagentes.

Os métodos com base na identificação / análise de proteínas são mais práticos, sendo o teste de fita bastante utilizado nos EUA, Argentina e Brasil, para detectar transgênicos a partir de amostras retiradas de caminhões. O teste de ELISA é muito mais preciso que os testes de fita, porém mais caro e demorado. Os testes com base em proteína não podem ser utilizados em alimentos que sofreram qualquer tipo de processamento, por isso o interesse prático na verificação de lotes com presença de OVMs, como no caso tratado neste trabalho.

\begin{tabular}{|c|c|c|c|c|c|}
\hline \multirow{2}{*}{ Parâmetros } & \multicolumn{2}{|c|}{$\begin{array}{c}\text { Métodos Baseados na Análise de } \\
\text { Proteínas }\end{array}$} & \multicolumn{2}{|c|}{ Métodos Baseados na Análise de } \\
\cline { 2 - 6 } & $\begin{array}{c}\text { Imuno- } \\
\text { cromatográfico } \\
\text { (Testes de Fita) }\end{array}$ & ELISA & $\begin{array}{c}\text { PCR } \\
\text { Qualitativo }\end{array}$ & $\begin{array}{c}\text { PCR } \\
\text { Competitivo }\end{array}$ & $\begin{array}{c}\text { PCR em } \\
\text { Tempo Real }\end{array}$ \\
\hline Facilidade de uso & Simples & Moderada & Difícil & Difícil & Difícil \\
\hline Necessidade de equipamento especial & Não & Sim & Sim & Sim & Sim \\
\hline Sensibilidade & Alta & Alta & Muito Alta & Alta & Alta \\
\hline Duração & 10 minutos & 30 a 90 min. & 1,5 dias & 2 dias & 1 dia \\
\hline Fornece Resultados Quantitativos? & Não & Sim & Não & Sim & Sim \\
\hline Apropriado para testes de campo? & Sim & Sim & Não & Não & Não \\
\hline Custo/Amostra (US\$) & 2,00 & 5,00 & 250,00 & 350,00 & 450,00 \\
\hline
\end{tabular}

Fonte: Silveira et al, 2006.

\footnotetext{
${ }^{12}$ Sistemas tidos como soft envolvem predominantemente gastos com documentação, usando anotações nos documentos fiscais. Os sistemas hard são baseados em sistemas de aplicação de testes de identificação - qualitativos e quantitativos - da presença de grãos OVMs nos lotes e pela retirada de amostras de controle, que são armazenadas para futura averiguação em caso de problemas. São claramente mais custosos e interferem na logística de transporte e armazenamento, como será tratado adiante.
} 
Percebe-se, por meio das informações registradas no Quadro 2, que é expressiva a dimensão dos custos por amostra, além de prazos diferenciados para a obtenção de resultados dos testes, que definem o escopo da relação custo/benefício, envolvendo a escolha entre qualidade (entendida como precisão e acurácia dos resultados) e aplicabilidade. Sistemas que demandem o conhecimento da quantidade de cada OVM em um lote amostrado exigem o uso de PCR ${ }^{13}$ em tempo real, que além de ser um equipamento caro, necessita de qualificação técnica para sua operação. (Silveira et al, 2006).

O detalhamento dos procedimentos para identificação de lotes de OVMs devem determinar o tipo de teste a ser utilizado, o que pode ser considerado um fator gerador de custos diretamente atribuíveis ao PCB. Todavia, como será visto a seguir, existem custos que são indiretos, derivados da adaptação requerida, para que o sistema funcione de maneira adequada: custos de reorganização da logística de transporte e armazenamento e também custos implícitos de não-adoção da tecnologia, quando aplicáveis.

A obtenção de um guia de procedimentos "detalhados" é que gera a tensão entre exportadores e importadores, um conflito cujo fórum é o PCB, especificamente a MOP. Dos países que compõem este grupo, é comum observar-se que seus Ministérios de Meio Ambiente adotam como política a imposição de barreiras à adoção de cultivares transgênicos. A eles se juntam os países predominantemente importadores de grãos, como a China e Índia, que percebem que a imposição, oriunda do PCB, lhes fornece uma base para melhor negociar seus contratos, invocando a questão de biossegurança toda vez que lhes parecer conveniente.

A expressão "pode conter", portanto, é contrária ao interesse destes dois grupos de países, uma vez que dá ao exportador o direito de informar, de maneira genérica, que o lote "pode conter OVMs" ou não. A declaração da "ausência de grãos OVMs" no lote exportado ficaria sob responsabilidade dos países importadores. Assim, com a expressão "pode conter", os custos do sistema de certificação passariam quase integralmente para os agentes importadores. ${ }^{14}$

Os países que defendem a identificação com base na expressão "contém OVMs" acreditam que, somente com a realização de testes rigorosos, a biossegurança dos OVMs poderá ser comprovada e assegurada. Estes países defendem que a identificação deverá requerer testes para verificar:

i. a existência de OVMs no carregamento em questão,

ii. os eventos OVMs específicos que estão presentes (por exemplo: soja e milho resistentes a pragas e tolerantes a herbicidas) e

iii. a porcentagem ou a quantidade de cada evento presente no carregamento.

Dependendo do grau de exigência, associado aos três pontos e às condições do país produtor, no que tange à logística de transporte e armazenamento, a expressão "contém" poderia resultar em forte desestímulo à adoção de cultivares transgênicos.Pode-se perceber que, sendo a natureza do impacto sujeita a controvérsias, a previsão de seus impactos é ainda mais incerta. Porém, o artigo se propõe a apresentar resultados de trabalhos acadêmicos que procuraram avaliar - sob a condição imposta por pressupostos simplificadores - os possíveis impactos, para exportadores e importadores (e também para países parte e não-parte do PCB), da aplicação do protocolo, de acordo com o que se prevê que possa vir a ser a regulamentação do artigo 18.2.(a).

\section{Impactos do Protocolo de Cartagena no Comércio Agrícola Mundial}

\section{Os Custos de Conformidade ao Protocolo de Cartagena}

Os Custos de Conformidade (compliance costs) ao Protocolo de Cartagena correspondem aos custos

${ }^{13}$ PCR (Polymerase Chain Reaction ) é um método de amplificação de DNA.

${ }^{14}$ É claro que o "repasse dos custos, em situações de estruturas competitivas de mercado, irá depender da elasticidade de demanda e oferta, ou seja, das funções de transferência das commodities. Em situações de preços desfavoráveis - como a do ano de 2005/6, os custos de um sistema rigoroso de identificação de cargas seria transferido para os países exportadores. 
dos recursos necessários para o cumprimento das determinações legais estabelecidas pelas partes. Resumindo o que foi apresentado na seção 2, os custos dependem:

1) da natureza da identificação dos OVMs que serão requeridos,

2) da posição do país no mercado mundial de commodities agrícolas: se o país é exportador ou importador, se é produtor de cultivos GM, e

3) das condições internas de cada país, como as condições de logística e da capacidade técnica para realizar os testes com segurança e com baixo custo.

Como visto no Quadro 2, o uso da expressão "contém OVMs" exigirá o uso de testes mais complexos, mais caros e que demandam mais tempo para serem aplicados, situações que afetam principalmente a logística de transporte.

\section{A Natureza da Identificação de OVMs e o Impacto no Custo}

Estudos realizados no Brasil, Argentina e Estados Unidos mostram que os custos da realização de testes de OVMs aumentam com o número de amostras que serão analisadas, com o tipo de avaliação requerida pelo Protocolo (identificação simples, usando teste de proteína, avaliação qualitativa, avaliação quantitativa), com o número de eventos que serão testados e o número de cultivos que serão avaliados (Silveira et al, 2006; Kalaitzandonakes, 2005).

A existência de dois eventos e seis variedades diferentes podem resultar em elevados custos para a identificação e quantificação destes eventos. A Tabela 2 mostra as estimativas elaboradas com relação às exportações de milho dos Estados Unidos em 2004. Foram calculados considerando os 3.575 carregamentos ${ }^{15}$ exportados anualmente, ou seja, 71,5 milhões de toneladas.

Os resultados mostram que os custos aumentariam expressivamente caso fosse necessário identificar e quantificar os eventos. A estimativa feita por Kalaitzandonakes, (2005) estabelece um contraste entre o caso em que apenas uma amostra é analisada no porto - utilizando os métodos de DNA - e o caso em que 20 amostras são submetidas às análises ao longo da cadeia. Ainda que economias de escala possam existir quando um maior número de análises é feita, a estimativa permite perceber que apenas para dizer se um lote tem ou não cultivares transgênicos - sem identificá-los e, menos ainda, quantificá-los - pode-se despender cerca de US $\$ 20$ milhões/ano, o que representa, aproximadamente, $0,1 \%$ do valor de toda a safra de milho dos EUA. Estes montantes aumentam progressivamente, alcançando US $\$ 87$ milhões, cerca de $0,5 \%$ do valor da safra do país em questão.

Desde já, pode-se apontar para o fato de que as estimativas elaboradas para os EUA não levam em conta os custos adicionais do processo de identificação de cargas de grãos para exportação. Os autores não se deram conta do fato de que a identificação detalhada, utilizando o método do PCR quantitativo, não teria grande utilidade se não fosse conduzida paralelamente à segregação de cargas e ao uso de pelo menos 4 amostras destinadas à identificação da origem - a lavoura em que o transgênico $X$ foi cultivado - da possível contaminação que colocaria em risco a biodiversidade e/ou a saúde humana.

Tabela 2. Custos de Conformidade ao Protocolo de Cartagena: produção de milho nos Estados Unidos

\begin{tabular}{c|c|c|c|c}
\hline $\begin{array}{c}\text { No de amostras } \\
\text { testadas }\end{array}$ & $\begin{array}{c}\text { Carregamentos } \\
\text { testados }\end{array}$ & $\begin{array}{c}\text { Identificação } \\
\text { simples (US\$) }\end{array}$ & $\begin{array}{c}\text { Identificação dos } \\
\text { eventos (US\$) }\end{array}$ & $\begin{array}{c}\text { Quantificação dos } \\
\text { eventos (US\$) }\end{array}$ \\
\hline 1 & 3.575 & $936.650(100)$ & 2.343 .900 & 4.356 .900 \\
20 & $18.733 .000(100)$ & 46.848 .000 & 87.138 .000 \\
\hline
\end{tabular}

Fonte: Kalaitzandonakes, 2005.

${ }^{15}$ Cada carregamento contém 20.000 toneladas de milho, dando uma idéia aproximada do número de navios envolvidos. Todavia, navios do tipo Panamax podem chegar até 70.000 toneladas de grãos por viagem. Ver Silveira et al, 2006. 
Apesar da inexistência, até o momento, de um estudo detalhado para os EUA, os dados referentes ao estudo FAO/SAGAyP (2004), apresentados na seqüência, mostrarão o significativo impacto da reorganização interna da logística de transporte e armazenamento, mesmo em um país com condições favoráveis para a aplicação de métodos, como é o caso da Argentina. O Brasil estaria na pior posição, uma vez que o tempo médio estimado para o processo de exportação é de 29 dias. Toda e qualquer medida, que resultasse em mudança de método para a implantação de sistemas de segregação e rastreabilidade, acarretaria em atraso nas exportações. (Silveira et al. 2006).

\section{A Posição no Mercado Mundial: o efeito do PCB sobre o comércio mundial}

Como foi visto, ser país parte ou não-parte do PCB é menos importante do que ser exportador de grãos, quando se trata dos impactos da implantação do PCB.

Um grupo de países, classificado na categoria de "grandes exportadores" de grãos e que não ratificou e incorporou o PCB, como EUA, Argentina, Austrália e Canadá, tornou-se, de certa forma, "fiel na balança" no jogo que continua após a MOP3. Em tese, a não adesão ao PCB não eximiria estes países de seguir as regras definidas pelos "paísesparte”, no caso do comércio país não-parte (origem) e parte (destino).

Neste sentido, os idealizadores do Protocolo, inspirados nos instrumentos desenhados para regular a doação de pesticidas pela FAO (SILVEIRA, 1994), o imaginaram como sendo "auto-realizável", ou seja, que o PCB seria capaz de impor suas regras inclusive para os países não-parte, pela força das exigências dos países parte importadores de commodities. Tal raciocínio não considera o poder dos acordos bilaterais, que podem levar os países-parte a reduzir suas exigências e com isto os possíveis impactos econômicos resultantes da aplicação das regras do PCB.

No curto prazo, quanto aos impactos previstos, a implementação do PCB afetaria os principais segmentos do comércio agrícola mundial e os principais países exportadores de commodities agrícolas, já que estes integram o grupo formado pelos maiores produtores de cultivos GM.

No médio e longo prazos, um duplo efeito pode ocorrer: por um lado, a ampliação do escopo da biotecnologia agrícola sugere tanto o aumento da área e do número de cultivos GM, quanto uma maior complexidade resultante da existência de um maior número de eventos em um mesmo lote destinado à exportação; por outro lado, o efeito de curto prazo pode resultar na redução do volume de comércio de grãos GM e também do montante exportado de grãos em relação à exportação de produtos processados.

Tal "desvio de comércio" (SILVEIRA et al, 2006) também teria um duplo efeito: encarecer a matéria-prima, caso esta passasse a ser produzida em países de grandes importadores, no período anterior ao início do efeito do PCB, como China e União Européia (EU) ou incentivar a exportação de produtos semi-industrializados, como farelo de soja ou mesmo a exportação de rações prontas. ${ }^{16}$

Uma outra possibilidade decorreria do fato de que a implementação do PCB, no que se refere ao processo de identificação de OVMs destinados à exportação, impõe um custo fixo aos participantes da cadeia de grãos e derivados. Em situações como a atual, em que a combinação de preços baixos e câmbio sobrevalorizado, a imposição de custos adicionais para a preservação de identidade poderia induzir ao lento abandono dos cultivares transgênicos ou, em oposição, o desaparecimento dos cultivares não-transgênicos e o reconhecimento pelo país, via técnicas de Preservação de Identidade (PI) através de documentação, de que toda sua produção seria transgênica.

$\mathrm{Na}$ Tabela 3 são mostrados os países que representam 90\% do comércio agrícola mundial. Entre os grandes exportadores líquidos, apenas Brasil, Índia e Nova Zelândia são signatários do Protocolo. Os demais exportadores - Argentina, Austrália, Canadá e Estados Unidos - não são signatários do Protocolo. Entretanto, como foi visto, em tese isso não os excluiria da necessidade de atender às obrigações do Protocolo, uma vez que os 
países importadores signatários poderiam exigir a identificação. No caso da soja, por exemplo, dos três principais exportadores, o Brasil é o único signatário. Os outros dois - Estados Unidos e Argentina - não o são, mas provavelmente terão que atender às exigências do Protocolo, uma vez que os principais importadores - União Européia, China, Japão e México - são signatários e poderão exigir a identificação de acordo com o estabelecido pelo Protocolo.

Tabela 3. Saldo da Balança Comercial de Produtos Agropecuários em 2005: Países Selecionados (US\$1000)

\begin{tabular}{ccccc}
\hline Países & $\begin{array}{c}\text { Produtos } \\
\text { Agropecuários }\end{array}$ & Soja & Milho & $\begin{array}{c}\text { Posição em relação ao } \\
\text { Protocolo de Cartagena }\end{array}$ \\
\hline Brasil & 23.616 .930 & 5.321 .123 & 561.409 & Signatário \\
Austrália & 16.400 .465 & 795 & 4.121 & Não Signatário \\
Argentina & 14.953 .141 & 1.591 .601 & 1.189 .258 & Não Signatário \\
Nova Zelândia & 8.241 .267 & -483 & -1.519 & Signatário \\
Canadá & 5.379 .636 & 144.447 & -192.918 & Não Signatário \\
Estados Unidos & 4.019 .016 & 6.630 .602 & 5.997 .216 & Não Signatário \\
Índia & 1.950 .114 & 761 & 155.229 & Signatário \\
União Européia (25) & -3.240 .871 & -4.503 .595 & -713.014 & Signatário \\
México & -3.559 .357 & -1.106 .310 & -737.707 & Signatário \\
China & -15.556 .970 & -7.535 .482 & -494.347 & Signatário \\
Japão & -39.604 .945 & -1.774 .405 & -2.931 .825 & Signatário \\
\hline
\end{tabular}

Fonte: FAOSTAT, 2006.

A Tabela 4 mostra os efeitos do Protocolo sobre o nível de preços da soja em diferentes mercados. Como esperado, em uma simulação realizada por HUANG et al. (2006), depois da implementação do Protocolo de Cartagena, os preços internacionais de soja e de milho aumentariam ${ }^{17}$. Conforme a Tabela 4, dependendo de qual cenário de identificação de OVMs for considerado, o preço internacional de soja aumentaria de 0,07 para 0,11.
De forma similar, o preço internacional do milho aumentaria em uma maior proporção (de 0,31 para 1,07), refletindo custos relativos maiores por tonelada e a natureza mais complicada dos testes. Ao comparar os preços domésticos, o mercado chinês acompanharia o mercado internacional, enquanto que, ao analisar o NAFTA ${ }^{18}$ e Américas do Sul e Central, os preços domésticos apresentariam uma queda.

Tabela 4. Estimativas dos Impactos percentuais nos preços internacionais e domésticos de soja e milho com a implementação do Protocolo de Biossegurança nos três alternativos cenários - 2010

\begin{tabular}{|c|c|c|c|c|c|c|}
\hline \multirow{2}{*}{ R e g i õ es } & \multicolumn{3}{|c|}{ So ja } & \multicolumn{3}{|c|}{ M ilho } \\
\hline & Pode conter & Identific a ção & Q u an tificação & Pode conter & Id en tific ação & Q u antific ação \\
\hline Preços internacionais & 0,07 & 0,1 & 0,11 & 0,31 & 0,56 & 1,07 \\
\hline $\begin{array}{c}\text { Preços dom ésticos } \\
\text { China }\end{array}$ & 0,06 & 0,08 & 0,1 & 0,09 & 0,17 & 0,33 \\
\hline $\mathrm{N}$ A F T A & $-0,03$ & $-0,05$ & $-0,07$ & $-0,05$ & $-0,09$ & $-0,17$ \\
\hline $\begin{array}{c}\text { A m éricas do Sul } \\
\text { e Central }\end{array}$ & $-0,02$ & $-0,03$ & $-0,04$ & $-0,04$ & $-0,07$ & $-0,13$ \\
\hline
\end{tabular}

Fonte: HUANG et. al. (2006) 
Ao analisar os impactos produtivos, é possível observar que, tendo por base a Tabela 5, haveria uma queda da produção no NAFTA e nas Américas do Sul e Central. No caso da China, a produção interna aumentaria. Diante de um aumento do preço doméstico da China, os mercados de soja e milho seriam estimulados, fazendo com que houvesse um aumento produtivo nos três cenários considerados.
Quanto maior for o preço doméstico, devido à implementação do Protocolo de Cartagena, os produtores responderiam produzindo uma maior quantidade, pois os mesmos buscariam maiores preços. O contrário ocorreria nas regiões onde o preço doméstico fosse reduzido, desestimulando a entrada de novos produtores no mercado, os quais pudessem aumentar a produção.

Tabela 5. Impactos na produção (milhões de dólares) de soja e milho com a implementação do Protocolo de Biossegurança nos três alternativos cenários - 2010

\begin{tabular}{|c|c|c|c|c|c|c|}
\hline \multirow{2}{*}{ R e giõ es } & \multicolumn{3}{|c|}{ So ja } & \multicolumn{3}{|c|}{ M ilho } \\
\hline & Podeconter & Identificação & Q uantificação & Pode conter & Identific açã & Q u antificação \\
\hline M undo & 3,1 & 4,2 & 4,6 & 8,5 & 17,3 & 33,4 \\
\hline $\mathrm{C}$ hin a & 4,1 & 5,4 & 5,9 & 10,8 & 21,7 & 41 \\
\hline N A F T A & $-7,4$ & $-9,6$ & $-9,8$ & $-20,6$ & $-41,2$ & $-77,3$ \\
\hline $\begin{array}{c}\text { A méricas do Sul } \\
\text { e Central }\end{array}$ & $-6,9$ & $-9,7$ & $-11,6$ & $-7,5$ & $-14,9$ & $-27,7$ \\
\hline
\end{tabular}

Fonte: HUANG et. al. (2006)

Tal situação aconteceria, uma vez que o ônus de toda implementação dos custos associados ao Protocolo recairia sobre os países exportadores de soja e milho para o mercado chinês. Percebe-se com isto a razão da China, na atualidade, ter ratificado e incorporado o PCB e ser defensora da exigência de identificação de OVMs, com a quantificação da presença de grãos modificados nos lotes importados pelo país. Ao transferir o custo de testes para os países exportadores, o aumento dos preços externos induziria uma elevação da produção interna. Estes resultados estão associados ao fato da China ser um importante importador de soja e milho e não um exportador, pelo menos no caso da soja.

É importante notar que os resultados da simulação mostram um efeito semelhante à aplicação de um imposto - mais um, no caso do Brasil, reduzindo o preço recebido pelas regiões produtoras/exportadoras e elevando o preço nos países consumidores, com notória perda de bemestar em todo sistema econômico. Tal conclusão, sugere portanto, não só cuidado na implantação do
PCB, mas o uso do princípio da precaução aplicado ao próprio processo regulatório, pois não haveria razão para implantar sistemas excessivamente rigorosos de identificação de cargas OVMs sem respeitar, caso a caso, as indicações fornecidas pelas análises de risco.

\section{As Condições Internas nos Países Exportadores}

Os impactos do Protocolo serão distintos mesmo entre os países exportadores. A diferença entre eles se explica pelas condições de logística, pela infra-estrutura de testes de identificação e pela participação das exportações na produção. A diferença de custos entre os países exportadores poderá afetar suas competitividades e causar desvios de comércio.

O trabalho de Silveira et al (2006), tratando do caso do Brasil e especificamente do impacto do PCB sobre a cultura da soja, mostra que existem grandes diferenças entre as estruturas de transporte dos principais países exportadores de grãos. $\mathrm{Na}$

\footnotetext{
${ }^{16}$ Vale lembrar que países como Índia e China vêm impondo elevadas tarifas aos produtos semi-industrializados exportados pelo Brasil, com taxas em torno de 30\%, o que incentiva a exportação de grãos. O PCB poderia, portanto, mudar drasticamente a composição do comércio internacional de grãos.

${ }^{17}$ Os impactos de aumento de custo pela implementação do Protocolo de Biossegurança no mercado chinês foram analisados pelo Global Trade Analysis Project (GTAP), juntamente com a estimativa dos custos de testes por amostras e por toneladas importadas. Todas as hipóteses e fontes de dados foram especificadas em HUANG et al. (2006).

${ }^{18}$ Tratado comercial entre países da América do Norte.
} 
Argentina, um fator importante de competitividade é a reduzida distância das áreas produtivas até o porto (inferiores em média a $250 \mathrm{~km}$ ), o que favorece o transporte rodoviário (82\%), que é mais custoso que os outros modais, mas bastante ágil. Nos Estados Unidos, as distâncias percorridas pelas cargas são mais longas, mas o país tem a vantagem de ter $61 \%$ dos carregamentos transportados por hidrovias, que além de apresentar o menor custo, reduz o número de transbordos, reduzindo assim o número de testes de identificação das cargas. O Brasil, em relação aos seus dois principais concorrentes, permanece em desvantagem pela distância média entre o local de produção e os portos (acima de $1.000 \mathrm{~km}$ ), pela grande dependência das rodovias $-60 \%$ do total transportado, na estimativa da Associação Brasileira de Óleos Vegetais, ABIOVE, citada por Silveira et al, 2006 - e pela quantidade excessiva de transbordos (3 ou mais, para alcançar os portos).

Há uma relação estreita entre as condições de transporte e armazenamento de grãos e a avaliação de impactos do Protocolo de Cartagena. Quanto mais distante dos portos estiver a zona de produção, maior a necessidade de transbordos para escoar uma determinada carga de grãos. Os estudos realizados por FAO/SAGPyA (2004), ao selecionarem "zonas propícias" para segregação em níveis compatíveis com limiares de rotulagem $(0,9 \% ; 1 \%)$, apontaram as limitações impostas à introdução do processo de preservação de identidade em regiões situadas a mais de $350 \mathrm{~km}$ do porto.
A existência de armazéns intermediários, privados ou de cooperativas, também dificulta o processo de identificação. Tais armazéns têm capacidade de estoque elevada, em torno de 30.000 a 60.000 toneladas. Ainda de acordo com FAO/ SAGPyA (2004), tais volumes são incompatíveis com programas de certificação com base em níveis reduzidos de presença adventícia.

No caso específico do Brasil, apesar do transporte por caminhão ter predominância, a combinação com o sistema ferroviário e, em menor proporção, com hidrovias, implica a formação de "lotes" com volume muito superior ao recomendado em caso de identificação de presença adventícia além do limite desejado. A qualidade das estradas, o déficit na capacidade de armazenagem no campo e os armazéns intermediários, além da existência de sazonalidade nas exportações, levam as empresas a buscarem a otimização ao longo do caminho percorrido pela carga. Tais práticas, para a grande porcentagem da carga escoada, não são compatíveis com processos de segregação. No caso da produção de soja, a regiões produtoras apresentam diferenças quanto à distância aos portos, aos meios de transportes e às condições de armazenamento. Estas diferenças implicariam em custos diferenciados para concretizar a segregação. Como mostra a Tabela 6, o custo total para segregação chegaria a $8 \%$ do preço da soja no Sudeste do Mato Grosso, enquanto que no Rio Grande do Sul este custo seria de apenas $0,2 \%$.

Tabela 6. Estimativa do aumento de custos logísticos da produção de soja com segregação e certificação para as principais regiões produtoras brasileiras, comparada com o preço médio da soja por região (R\$/ toneladas)

\begin{tabular}{|c|c|c|c|c|c|c|c|}
\hline \multirow{2}{*}{ Região } & \multirow{2}{*}{ Principais Rotas } & \multicolumn{4}{|c|}{ Aumento de Custo (R\$/Tonelada) } & \multirow{2}{*}{$\begin{array}{c}\text { Preço } \\
(\mathrm{R} \$ / \text { tonelada })\end{array}$} & \multirow{2}{*}{$\begin{array}{l}\text { Custo Total } \\
(\% \text { do Preço) }\end{array}$} \\
\hline & & Transporte & Armazenagem & Testes & Total & & \\
\hline \multirow{5}{*}{$\begin{array}{l}\text { Sudeste do } \\
\text { Mato Grosso }\end{array}$} & Rondonópolis - Paranaguá & 30,5 & 13,4 & 1,2 & 45,1 & 523,3 & $8,6 \%$ \\
\hline & $\begin{array}{c}\text { Rondonópolis - Alto } \\
\text { Taquari - Santos }\end{array}$ & 24,4 & 10,7 & 1,5 & 36,6 & 523,3 & $7,0 \%$ \\
\hline & $\begin{array}{l}\text { Rondonópolis - } \\
\text { Uberlândia - Vitória }\end{array}$ & 24,4 & 10,7 & 1,5 & 36,6 & 523,3 & $7,0 \%$ \\
\hline & Rondonópolis - Santos & 24,4 & 10,7 & 1,2 & 36,3 & 523,3 & $6,9 \%$ \\
\hline & $\begin{array}{l}\text { Rondonópolis - Porto } \\
\text { Velho - Itacoatiara }\end{array}$ & 18,3 & 8 & 1,9 & 28,2 & 523,3 & $5,4 \%$ \\
\hline \multirow{3}{*}{$\begin{array}{l}\text { Rio Grande } \\
\text { do Sul }\end{array}$} & Passo Fundo - Rio Grande & 0 & 0 & 1,2 & 1,2 & 616,7 & $0,2 \%$ \\
\hline & Passo Fundo-Rio Grande & 0 & 0 & 1,2 & 1,2 & 616,7 & $0,2 \%$ \\
\hline & Passo Fundo-Rio Grande & 0 & 0 & 1,5 & 1,5 & 616,7 & $0,2 \%$ \\
\hline
\end{tabular}

Fonte: Elaborada pelos autores. 
A predominância de terminais públicos nos principais portos brasileiros, sua configuração e a falta de condições adequadas para o estacionamento de caminhões nos portos implicam o uso de terminais próprios (ou alugados), específicos para produtos certificados como não-OVMs em escalas que não superam, para grãos, $20 \%$ do volume total exportado. Tal reorganização portuária envolveria custos muito elevados, de difícil avaliação (Silveira et al, 2006).

\section{Considerações Finais}

A idéia central do texto é mostrar como a regulação, no caso de biossegurança, tem importância crucial na adoção de tecnologias e no comércio de produtos, favorecendo alguns países e prejudicando outros. Cabe ao regulador, principalmente aquele focado nas questões científicas e tecnológicas, permanecer atento para o uso que certos participantes do jogo regulatório, - os que estão sob a proteção de protocolos internacionais - fazem de sua posição privilegiada no processo, visando criar "barreiras técnicas" ao comércio.
Para os países exportadores de OVMs, o uso da expressão "contém OVMs", com identificação e quantificação dos eventos, causará aumento desnecessário dos custos, pois a biossegurança não advém dos testes de identificação, mas da análise de cada produto antes de ser liberado para a produção comercial. Este tipo de identificação traria a necessidade de testes em cada carregamento, "sem trazer benefícios diretos para a conservação da biodiversidade, uma vez que são produtos não destinados à liberação no meio ambiente e que, se foram autorizados pelo país exportador, estão respaldados por análises de risco que garantem sua segurança".

Expressiva parcela dos acordos envolvendo regulação do fluxo de commodities entre fronteiras interage com as determinações que visam proteger o livre comércio, regulamentadas por acordos no âmbito da Organização Mundial do Comércio, OMC. $\mathrm{O}$ argumento baseado na proteção ambiental não pode, portanto, desconsiderar as implicações econômicas das decisões tomadas, sob pena de criarem desvios de comércio que interfiram de forma substantiva no desenvolvimento dos países.

Quadro 3. Síntese das posições dos exportadores de soja frente ao Protocolo de Cartagena

\begin{tabular}{|c|c|c|c|c|c|c|}
\hline \multirow{2}{*}{$\begin{array}{c}\text { Países } \\
\text { Exportadores } \\
\text { de Soja }\end{array}$} & \multicolumn{2}{|c|}{$\begin{array}{c}\text { Inserção no mercado } \\
\text { mundial }\end{array}$} & \multicolumn{2}{|c|}{ Condições de Logística } & \multirow[b]{2}{*}{$\begin{array}{l}\text { Signatário do } \\
\text { Protocolo }\end{array}$} & \multirow[b]{2}{*}{$\begin{array}{c}\text { Custo de } \\
\text { conformidade } \\
\text { ao Protocolo }\end{array}$} \\
\hline & $\begin{array}{c}\text { Exportação } \\
\text { de grãos }\end{array}$ & $\begin{array}{l}\text { Exportação } \\
\text { de derivados }\end{array}$ & $\begin{array}{l}\text { Distância } \\
\text { média entre } \\
\text { a produção } \\
\text { e os portos }\end{array}$ & $\begin{array}{l}\text { Número } \\
\text { médio de } \\
\text { transbordos }\end{array}$ & & \\
\hline Argentina & $31 \%$ & $69 \%$ & $200 \mathrm{~km}$ & 2 & Não & Baixo \\
\hline Brasil & $57 \%$ & $43 \%$ & $>1000 \mathrm{~km}$ & 3 a 4 & Sim & Alto \\
\hline Estados Unidos & $81 \%$ & $19 \%$ & $>1000 \mathrm{~km}$ & 2 & Não & Baixo \\
\hline
\end{tabular}

Fonte: elaboração dos autores.

O Quadro 3 sintetiza, para o caso da soja, que é de grande interesse do Brasil o efeito sobre o comércio que a implementação de regras do PCB considerando um padrão de média exigência, envolvendo testes e algum tipo de segregação de cargas - acarretará sobre os três principais países exportadores de grãos.

Um efeito menor, mas não desprezível, apontado no trabalho, é o de incentivar a produção de grãos em países menos competitivos, como China e países da União Européia. Uma das sugestões importantes é que a implementação do PCB seja acompanhada de gestões para redução das tarifas impostas por países importadores, e China, às exportações de produtos semi-processados, principalmente farelos destinados à alimentação animal, o que atenuaria o impacto derivado da implementação do protocolo, por tratar-se de exportação de produtos que de forma alguma podem 
ser relacionados com biossegurança.

\section{Referências Bibliográficas}

CONSELHO DE INFORMAÇÕES SOBRE BIOTECNOlOGiA (CIB). Protocolo de Cartagena sobre Biossegurança: Impactos para o Brasil, 2006. Disponível em www.cib.org.br

FAO \& SAGPyA. Evaluación de la capacidad, infraestructura y logística de manejo post-cosecha de organismos vivos modificados e identificación de estrategias para aplicar el artículo 18, 2.a del protocolo de cartagena sobre seguridad de la biotecnología, 2006. Disponível em: www.fao.org/AG/AGP/ AGPS/SEED/Doc3fin.pdf

FAOSTAT - FOOD AND AGRICULTURE ORGANIZATION OF THE UNITED NATIONS - FAO. Statistical Databases (vários anos). Disponível em: http://www.fao.org. 2006.

HALL, J.; MARTIN, M. Radical New Technology, Stakeholders and the Innovation Value Chain: An Innovator's Predicament. R\&D Management Journal, 2003.

HUANG, J. ZHANG, D., YANG, J., ROZELLE, S., KALAITZANDONAKES, N. The potential impacts of the biosafety protocol: perspective of China - a major importer. Washington: International Food and Agricultural Trade Policy Council, 2006.

JAMES, C. Preview: Global Status of Commercialized Transgenic Crops: 2005. IS AAA Briefs. ISAAA: Ithaca, NY, 2006. Disponível em: www.isaaa.org

KAlaitZandonakes, N. The Potential Impacts of the Biosafety Protocol on Agricultural Commodity Trade. International Food \& Agricultural Trade, Issue Brief, December 26, 2004. Disponível em www.agritrade.org

RUNGE, C. F.; RYAN, B. The Global Diffusion of Plant Biotechnology: International Adoption and Research in 2004. Disponível em: http:// www.apec.umn.edu/faculty/frunge/ globalbiotech04.pdf

SILVEIRA, J. M. F. J. Some Notes About Pesticides Industry in Brazil. In. WORSHOP ON PESTICIDES POLICIES, 1994, Germany Proceedings of Gottingen Workshop on Pesticidas Policies: Conceptual Framework on Pesticide Policies, Göttingen Universitat of Göttingen, 1994, v. $1, \mathrm{n}$.

SILVEIRA, J. M. F. J.; BORGES, I. C.; BUAINAIN, A. M. Biotecnologia e Agricultura: Da Ciência e Tecnologia aos Impactos da Inovação. São Paulo em Perspectiva, vol. 19, n 2, Abril-Junho 2005.

SILVEIRA, J. M. F. J.; BORGES, I. C.; VIEIRA FILHO, J. E.; PEREIRA, A.M. Impactos da implementação do Protocolo de Cartagena sobre o comércio de commodities agrícolas (Mimeo). Campinas: Instituto de Economia/ UNICAMP, 2006.

\section{Autores}

Izaías de Carvalho Borges - Economista, Doutorando em Economia/IE (UNICAMP) e Professor da CEA (PUCCAMP). Pesquisador do NEA- IE (UNICAMP). E-mail: icborges@eco.unicamp.br

José Maria F.J. da Silveira - Eng. Agrônomo, Doutor em Economia e Coordenador do Núcleo de Economia Agrícola e Ambiental - NEA/ Instituto de Economia IE (UNICAMP). Pesquisador do GEOPI/IG (UNICAMP)

José Eustáquio Vieira Filho - Economista, Doutorando em Economia do IE (UNICAMP) e da Universidade de Bordeaux-IV. Pesquisador do NEA - IE (UNICAMP)

Andrea M. Pereira - Administradora de Empresas, pesquisadora do NEA - IE (UNICAMP) e Mestranda do Curso de Desenvolvimento do IE (UNICAMP) 